\title{
Interaction between dietary acrylamide intake and genetic variants for estrogen receptor-positive breast cancer risk
}

\author{
Janneke G. F. Hogervorst ${ }^{1,2}$ (1) - Piet A. van den Brandt ${ }^{2} \cdot$ Roger W. L. Godschalk $^{3} \cdot$ Frederik-Jan van Schooten $^{3}$. \\ Leo J. Schouten ${ }^{2}$
}

Received: 15 August 2017 / Accepted: 21 January 2018 / Published online: 14 February 2018

(c) The Author(s) 2018. This article is an open access publication

\begin{abstract}
Purpose The association between dietary acrylamide intake and estrogen receptor-positive (ER+) breast cancer risk in epidemiological studies is inconsistent. By analyzing gene-acrylamide interactions for ER+breast cancer risk, we aimed to clarify the role of acrylamide intake in ER+ breast cancer etiology.

Methods The prospective Netherlands Cohort Study on diet and cancer includes 62,573 women, aged 55-69 years. At baseline, a random subcohort of 2589 women was sampled from the total cohort for a case-cohort analysis approach. Dietary acrylamide intake of subcohort members $(n=1449)$ and ER+breast cancer cases $(n=844)$ was assessed with a food frequency questionnaire. We genotyped single nucleotide polymorphisms (SNPs) in genes in acrylamide metabolism, sex steroid systems, oxidative stress and DNA repair. Multiplicative interaction between acrylamide intake and SNPs was assessed with Cox proportional hazards analysis, based on 20.3 years of follow-up.

Results Unexpectedly, there was a statistically non-significant inverse association between acrylamide and ER+ breast cancer risk among all women but with no clear dose-response relationship, and no association among never smokers. Among the results for 57 SNPs and 2 gene deletions, rs1056827 in CYP1B1, rs2959008 and rs7173655 in CYP11A1, the GSTT1 gene deletion, and rs1052133 in $h O G G 1$ showed a statistically significant interaction with acrylamide intake for ER+breast cancer risk.

Conclusions This study did not provide evidence for a positive association between acrylamide intake and ER+breast cancer risk. If anything, acrylamide was associated with a decreased ER+ breast cancer risk. The interaction with SNPs in CYP1BI and CYP11Al suggests that acrylamide may influence ER+breast cancer risk through sex hormone pathways.
\end{abstract}

Keywords Dietary acrylamide $\cdot$ Single nucleotide polymorphism $\cdot$ Estrogen receptor-positive breast cancer $\cdot$ Prospective cohort

Electronic supplementary material The online version of this article (https://doi.org/10.1007/s00394-018-1619-z) contains supplementary material, which is available to authorized users.

Janneke G. F. Hogervorst

jgf.hogervorst@maastrichtuniversity.nl

1 Centre for Environmental Sciences, Hasselt University, Diepenbeek, Belgium

2 Department of Epidemiology, School for Oncology and Developmental Biology (GROW), Maastricht University, Maastricht, The Netherlands

3 Department of Pharmacology and Toxicology, School for Nutrition and Translational Research in Metabolism (NUTRIM), Maastricht University, Maastricht, The Netherlands

\section{Introduction}

Acrylamide, a probable human carcinogen (IARC class 2A), was discovered in 2002 in various heat-treated carbohydraterich foods, such as cookies, potato crisps, French fries and coffee. Acrylamide is a small hydrophilic compound that is distributed throughout the body with the blood. In theory, it can thus cause cancer everywhere in the body. Acrylamide is a multisite carcinogen in rodents, in which it causes, among other, mammary gland tumors in females [1]. The mechanisms by which acrylamide causes mammary gland tumors in rodents are hypothesized to be genotoxicity and endocrine effects [1]. Since 2002, a few epidemiological studies have investigated the impact of dietary acrylamide intake on human cancer risks. The results of these studies 
for breast cancer are inconsistent. A recent meta-analysis did not show an increased risk of breast cancer overall, with a relative risk in the highest category of intake versus the lowest of 0.96 (95\% CI 0.91-1.02) [2]. However, our previous analysis in the Netherlands Cohort Study [3] and a Danish study using acrylamide hemoglobin adducts as a marker of internal acrylamide exposure [4] gave some indications for a positive association between acrylamide intake and estrogen receptor-positive $(\mathrm{ER}+)$ breast cancer risk. Nevertheless, the above-mentioned meta-analysis did not show an increased risk of this type of breast cancer associated with dietary acrylamide intake either [RR 0.98 (95\% CI 0.89-1.08)] [2].

In the present study, we investigated whether genetic make-up modifies the association between acrylamide and ER+ breast cancer risk, thereby contributing to evidence on acrylamide's possible mechanism of action and on the causality of the observed associations. We focused on ER+ breast cancer because of the hypothesized effect of acrylamide on sex hormones and the fact that two studies observed an increased acrylamide-associated risk with this subtype of breast cancer. For ER+ breast cancers, the involvement of sex hormones in their etiology is probably stronger than for estrogen receptor-negative breast cancers [5]. We selected SNPs in candidate genes in acrylamide metabolism and in mechanisms through which acrylamide is hypothesized to cause cancer: mechanisms involving sex hormones, oxidative stress, and DNA damage caused by glycidamide, acrylamide's genotoxic metabolite [6]. Previously, we investigated acrylamide intake and gene interactions for endometrial and ovarian cancer risk, and we observed indications for interaction between acrylamide intake and SNPs in among other cytochrome P450, family 2, subfamily $E$, polypeptide 1 (CYP2E1) and the deletions of the genes glutathione s-transferase M1 and TI (GSTMI and GSTT1) $[7,8]$.

\section{Subjects and methods}

\section{Study cohort, cases and follow-up}

The Netherlands Cohort Study on diet and cancer started in September 1986 with the inclusion of 62,573 women that were 55-69 years of age, all presumed to be post-menopausal. Data on dietary habits and other risk factors were collected by means of a self-administered questionnaire at baseline in 1986. In addition to the questionnaire, approximately $75 \%$ of the participants sent in toenail clippings, as requested.

Following the case-cohort approach, ER+ breast cancer cases were enumerated for the entire cohort, while the accumulated person-years for the entire cohort were estimated from a subcohort of 2589 women randomly sampled from the entire cohort at baseline. Since the start of the study, the subcohort has been followed up regularly for vital status information. Incident cancer cases in the total cohort have been detected by computerized record linkages to the Netherlands Cancer Registry, the Netherlands Pathology Registry and the causes of death registry. Further details on the design of the study and methods of follow-up are presented elsewhere [9-12].

After 20.3 years of follow-up, from September 1986 to December 2006, and after exclusion of cohort members who reported a diagnosis of cancer (except skin cancer) at baseline, there were 1620 microscopically confirmed invasive $\mathrm{ER}+$ primary carcinomas of the breast ([ICD-O]-3: C50). Information on estrogen receptor status was obtained from the National Cancer Registry and the Dutch Pathology Registry and was assessed by either immunohistochemistry or biochemical assay. Cases and subcohort members were excluded from analysis if their dietary data were incomplete or inconsistent, if they had not sent in toenail clippings, and if they had no or inferior (call rate $<95 \%$ ) data on SNPs. Figure 1 shows the selection and exclusion steps that resulted in the numbers of cases and subcohort members that were available for analysis.

\section{Acrylamide intake assessment}

A valid and reproducible food frequency questionnaire with questions on 150 food items was used for estimating dietary habits [11, 12]. Dietary acrylamide intake was estimated from the mean acrylamide level of foods on the Dutch market, and the frequency of consumption and portion size of the foods, as described in detail elsewhere [13].

\section{Selection of genes and SNPs}

The selection of genes focused on genes involved in (1) acrylamide metabolism and (2) the most often hypothesized mechanisms of acrylamide-induced carcinogenesis [6]: (2a) sex hormonal effect (involving sex hormone synthesis/metabolism or sex hormone nuclear receptors), (2b) oxidative stress and (2c) genotoxicity (DNA repair), or (2d) SNPs in genes that have clearly been shown in the literature to play a role in carcinogenesis. A detailed description of the selection of genes and SNPs is presented elsewhere [7].

In the end, we genotyped 6 SNPs to determine GSTM1 and GSTT1 deletions (3 SNPs each) and 60 SNPs in other genes, see Supplemental Table 1.

\section{DNA isolation and genotyping}

DNA was isolated from $15 \mathrm{mg}$ of toenail clippings, following the protocol developed by Cline et al. [14], in an optimised form [15]. Genotyping was performed by Agena in 
Netherlands Cohort Study on diet and cancer

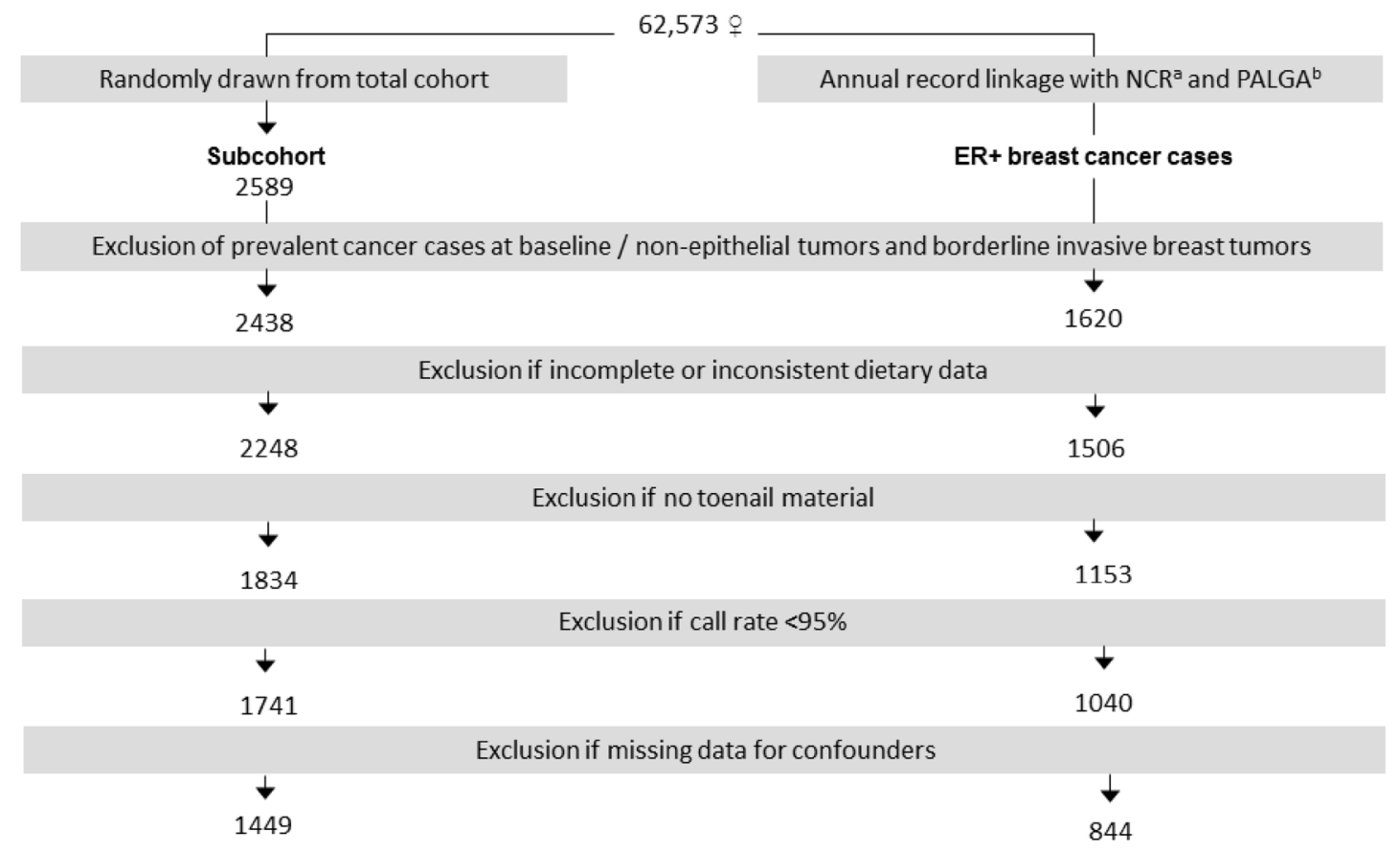

a Netherlands Cancer Registry

b Netherlands Pathology Registry

Fig. 1 Flow chart of subcohort members and estrogen receptor-positive breast cancer cases

Hamburg, on the MassARRAY platform using the iPLEX TM assay [16] This method has been successfully used before to genotype DNA from toenails [7, 15, 17, 18].

Supplemental Table 2 shows the 60 SNPs with their location, call frequencies, and HWE $p$ value. 3 out of the 60 SNPs that were genotyped had a call rate $<80 \%$ and were not included in the analyses. 6 SNPs out of the remaining 57 SNPs did not adhere to Hardy-Weinberg equilibrium (HWE) $(p<0.05)$. With regard to the SNPs selected to represent the GSTMI deletion, rs10857795 was not called in $36 \%$, rs 200184852 in $42 \%$ and rs 74837985 in only $2 \%$ of the subcohort. The latter value appears to be due to genotyping error. Therefore, we decided to base the assessment of the absence/presence of the GSTM1 gene only on rs10857795 and rs200184852. 31\% of the subcohort had a missing value for both rs 10857795 and rs200184852. With regard to GSTT1, rs2844008 was not called in $58 \%$, rs 4630 in $16 \%$, and rs 140309 in $11 \%$ of the subcohort. $8 \%$ of the subcohort had a missing value for all 3 GSTT1 SNPs.

$5 \%$ of the samples $(n=190)$ were duplicate samples in order to check the reproducibility of genotyping, which was $>99 \%$. We excluded samples with a call rate $<95 \%$ (113 breast cancer cases, 93 subcohort members).

\section{Statistical analysis}

Hazard rate ratios (HRs) and 95\% confidence intervals were obtained through Cox proportional hazards regression with STATA software (package 13), using the robust Huber-White sandwich estimator to account for additional variance introduced by sampling from the cohort. We checked the proportional hazards assumption using scaled Schoenfeld residuals.

Covariables selected for inclusion in the Cox proportional hazards analysis models were selected based on the literature: age, body mass index, height, age at menarche, age at menopause, age at first childbirth, parity, ever use of oral contraceptives, ever use of postmenopausal hormones, history of benign breast disease, family history of breast cancer and energy intake. Smoking status, the duration of smoking and the number of cigarettes per day were included in the model, because cigarette smoke contains acrylamide. Smokers have on average four times higher levels of acrylamide-hemoglobin adducts than non-smokers $[19,20]$. To eliminate the influence of acrylamide through smoking, we performed subgroup analyses restricted to never smokers. In addition, we checked the confounding potential of various dietary factors, e.g., alcohol, fibre, glycaemic index, but 
none changed the hazard ratio of acrylamide by more than $10 \%$. The main associations between SNPs and ER+ breast cancer risk were only adjusted for age.

Multiplicative interaction between acrylamide intake and SNPs was tested using product terms of the continuous acrylamide intake variable and genotype. For statistical power reasons, we used a dominant genetic model for all SNPs. Tests for acrylamide dose-response trends in strata of the genotypes were performed by fitting the mean acrylamide intake in the tertiles as a continuous variable.

We applied the false discovery rate method developed by Benjamini-Hochberg to adjust for multiple testing [21] with the expected proportion of false positives set at $20 \%$ [22, 23].

Two-sided $p$ values are reported throughout this paper.

\section{Results}

Table 1 shows the characteristics of the subcohort and $\mathrm{ER}+$ breast cancer cases at baseline. Cases reported to have fewer children and to more often be nulliparous than subcohort members. Cases reported more often to be current smokers, to have smoked more cigarettes and for a longer duration, and to have drunk more alcohol than subcohort members. They reported more often to have ever used postmenopausal hormone treatment and less often to have ever used oral contraceptives. Furthermore, cases reported more often to have a personal history of benign breast disease and family history of breast cancer.

There was a statistically non-significant inverse association between acrylamide and ER+ breast cancer risk after 20.3 years of follow-up in all women (HR of highest versus the lowest quintile of intake: 0.85 (95\% CI 0.66-1.09) and $0.94(0.88-1.00)$ per $10 \mu \mathrm{g} / \mathrm{day}$ increment of intake) but with no clear dose-response relationship. There was no association in never-smoking women (HR of highest versus the lowest quintile of intake: 1.18 (95\% CI 0.85-1.64) and 1.02 (0.93-1.11) per $10 \mu \mathrm{g} /$ day increment of intake) (Table 2).

Table 3 presents the SNPs showing a trend for ER+breast cancer over the number of variant alleles after 20.3 years of follow-up. None of the SNPs was statistically significantly associated with ER+ breast cancer risk after adjustment for multiple comparisons. There were some nominally statistically significant interactions. There was a statistically non-significant decrease in risk with an increasing number of variant alleles for rs2070959 in UDP glucuronosyltransferase family 1 member A complex (UGT1A) $(p$ trend $=0.08)$, rs4919682 and rs4919687 in cytochrome P450, family 17, subfamily A, polypeptide 1 (CYP17A1) ( $p$ trend $=0.07$ and 0.05 , respectively), rs915906 in CYP2E1 ( $p$ trend $=0.09$ ), and rs3219489 in human MutY homolog (hMYH) ( $p$ trend $=0.07$ ).
Table 1 Characteristics of subcohort and estrogen receptor-positive breast cancer cases

\begin{tabular}{|c|c|c|}
\hline Variable & $\begin{array}{l}\text { ER+ breast } \\
\text { cancer cases }\end{array}$ & Subcohort \\
\hline$n$ & 364 & 1474 \\
\hline \multicolumn{3}{|l|}{ Dietary variables } \\
\hline Acrylamide intake ( $\mu \mathrm{g} /$ day) & $20.6(11.3)$ & $21.0(11.8)$ \\
\hline Coffee (g/day) & $498(247)$ & $499(242)$ \\
\hline Dutch spiced cake (g/day) & $5.3(9.0)$ & $5.6(9.5)$ \\
\hline Cookies (g/day) & $13.4(11.5)$ & $13.7(10.6)$ \\
\hline Potato crisps (g/day) & $0.36(1.36)$ & $0.39(1.80)$ \\
\hline French fries (g/day) & $3.8(8.3)$ & $3.7(8.1)$ \\
\hline Alcohol intake (g/day) & $6.4(10.7)$ & $5.9(9.6)$ \\
\hline Total energy intake (kcal) & $1689(394)$ & $1688(396)$ \\
\hline \multicolumn{3}{|l|}{ Non-dietary variables } \\
\hline Age (years) & $61.2(4.2)$ & $61.4(4.3)$ \\
\hline Height (cm) & $166(6)$ & $165(6)$ \\
\hline $\mathrm{BMI}\left(\mathrm{kg} / \mathrm{m}^{2}\right)$ & $25.3(3.3)$ & $25.1(3.6)$ \\
\hline Age at menarche (years) & $13.5(1.8)$ & $13.7(1.8)$ \\
\hline Age at menopause (years) & $49.0(4.5)$ & $48.8(4.4)$ \\
\hline Parity, $n$ children & $2.5(2.0)$ & $2.8(2.2)$ \\
\hline \multicolumn{3}{|l|}{ Age at first childbirth } \\
\hline Nulliparous & 20.7 & 18.1 \\
\hline $15-19$ years & 1.5 & 2.0 \\
\hline 20-24 years & 19.3 & 20.7 \\
\hline $25-29$ years & 38.3 & 41.2 \\
\hline$>30$ years & 20.2 & 18.0 \\
\hline$n$ cigarettes per day & $5.0(8.1)$ & $4.5(7.7)$ \\
\hline$n$ cigarette smoking years & $12.0(16.1)$ & $11.2(15.6)$ \\
\hline \multicolumn{3}{|l|}{ Cigarette smoking status $\%$} \\
\hline Never smokers & 56.4 & 58.8 \\
\hline Former smokers & 22.0 & 21.2 \\
\hline Current smokers & 21.6 & 20.0 \\
\hline $\begin{array}{l}\text { Ever use of postmenopausal hormone } \\
\text { treatment, \% yes }\end{array}$ & 14.5 & 13.6 \\
\hline Ever use of oral contraceptives, $\%$ yes & 24.7 & 25.5 \\
\hline History of benign breast disease, $\%$ yes & 12.3 & 7.3 \\
\hline Family history of breast cancer, $\%$ yes & 14.1 & 8.4 \\
\hline
\end{tabular}

$n$ represents number of subcohort members or cases after exclusion of participants with prevalent cancer at baseline, incomplete or inconsistent dietary data, and a sample call rate $<95 \%$. The number of missing values varies for the variables in this Table

Table 4 shows the interactions between SNPs and acrylamide intake that remained statistically significant after adjustment for multiple comparisons.

The homozygous deletion of GSTT1, when represented by rs140309, showed a statistically significant interaction with acrylamide intake ( $p$ interaction $=0.01$ ) and this interaction remained statistically significant after adjustment for multiple testing (Benjamini-Hochberg adjusted $p$ value 0.19 ). The same interaction was observed for never smokers. Women 
Table 2 Main association between acrylamide intake and estrogen receptor-positive breast cancer risk, 20.3 years of follow-up

\begin{tabular}{|c|c|c|c|c|c|c|c|c|}
\hline $\begin{array}{l}\text { Main effect acryla- } \\
\text { mide }\end{array}$ & $N$ cases & $\begin{array}{l}\text { HR Per } 10 \mu \mathrm{g} / \text { day } \\
\text { increment }\end{array}$ & $\begin{array}{l}\text { HR Quin- } \\
\text { tile } 1\end{array}$ & HR Quintile 2 & HR Quintile 3 & HR Quintile 4 & HR Quintile 5 & $p$ trend \\
\hline All women & 1238 & $0.94(0.88-1.00)$ & $\operatorname{Ref}(1.00)$ & $0.88(0.69-1.11)$ & $1.01(0.79-1.29)$ & $0.93(0.73-1.20)$ & $0.85(0.66-1.09)$ & 0.37 \\
\hline $\begin{array}{l}\text { Never-smoking } \\
\text { women }\end{array}$ & 703 & $1.02(0.93-1.11)$ & $\operatorname{Ref}(1.00)$ & $1.08(0.78-1.49)$ & $1.44(1.04-2.01)$ & $1.34(0.96-1.86)$ & $1.18(0.85-1.64)$ & 0.17 \\
\hline
\end{tabular}

Hazard ratios (HR) are adjusted for age (years), age at menarche (years), age at menopause (years), age at first childbirth (nulliparous, 15-19 years, 20-24 years, 25-29 years, $\geq 30$ years), parity ( $n$ children), ever use of oral contraceptives (yes/no), ever use of postmenopausal hormone treatment (yes/no), height $(\mathrm{cm})$, body mass index $\left(\mathrm{kg} / \mathrm{m}^{2}\right)$, educational level (4 levels) energy intake (kcal/day), history of benign breast disease, family history of breast cancer, and in the analyses for all women: smoking status (never/ex/current smoker), smoking quantity ( $n$ cigarettes/day), smoking duration (smoking years)

Table 3 Genetic variants showing a trend for estrogen receptor-positive breast cancer risk, 20.3 years of follow-up

\begin{tabular}{|c|c|c|c|c|c|c|c|c|c|}
\hline \multirow[t]{2}{*}{$\begin{array}{l}\text { Main effects } \\
\text { SNPs }\end{array}$} & \multirow[t]{2}{*}{ Total $N$ cases } & \multicolumn{2}{|c|}{$\begin{array}{l}1 \text { or } 2 \text { variant alleles } \\
\text { versus homozygous wild } \\
\text { type }\end{array}$} & \multicolumn{2}{|c|}{$\begin{array}{l}1 \text { variant allele versus } \\
\text { homozygous wild type }\end{array}$} & \multicolumn{2}{|c|}{$\begin{array}{l}2 \text { variant alleles versus } \\
\text { homozygous wild type }\end{array}$} & \multirow[t]{2}{*}{$\begin{array}{l}p \text { trend } \\
\text { per } \\
\text { allele }\end{array}$} & \multirow{2}{*}{$\begin{array}{l}\text { Benjamini- } \\
\text { Hochberg } \\
\text { adjusted } p \\
\text { value* }\end{array}$} \\
\hline & & $N$ cases & $\operatorname{HR}(95 \% \mathrm{CI})^{\dagger}$ & $N$ cases & $\mathrm{HR}(95 \% \mathrm{CI})^{\dagger}$ & $N$ cases & $\mathrm{HR}(95 \% \mathrm{CI})^{\dagger}$ & & \\
\hline $\begin{array}{l}U G T 1 A, \\
\text { rs } 2070959\end{array}$ & 1040 & 536 & $0.87(0.75-1.02)$ & 450 & $0.88(0.75-1.04)$ & 86 & $0.83(0.62-1.10)$ & 0.08 & 0.84 \\
\hline $\begin{array}{l}\text { CYP17A1, } \\
\text { rs4919682 }\end{array}$ & 1039 & 477 & $0.82(0.70-0.95)$ & 392 & $0.79(0.67-0.93)$ & 85 & $0.95(0.71-1.28)$ & 0.07 & 0.84 \\
\hline $\begin{array}{l}\text { CYP17A1, } \\
\text { rs4919687 }\end{array}$ & 1040 & 494 & $0.82(0.71-0.96)$ & 407 & $0.81(0.69-0.96)$ & 87 & $0.89(0.67-1.18)$ & 0.05 & 0.84 \\
\hline $\begin{array}{l}C Y P 2 E 1, \\
\text { rs915906 }\end{array}$ & 1039 & 255 & $0.82(0.69-0.98)$ & 230 & $0.80(0.66-0.96)$ & 25 & $1.16(0.68-1.98)$ & 0.09 & 0.84 \\
\hline $\begin{array}{l}h M Y H, \\
\quad \text { rs3219489 }\end{array}$ & 1039 & 425 & $0.91(0.78-1.06)$ & 378 & $0.95(0.81-1.12)$ & 47 & $0.67(0.47-0.97)$ & 0.07 & 0.84 \\
\hline
\end{tabular}

${ }^{\dagger}$ Hazard ratios (HR) are adjusted for age

*Proportion of false positives threshold set at 0.2

with a homozygous deletion of the GSTTl gene were at a statistically significantly decreased acrylamide-associated risk of ER+ breast cancer [HR 0.35 (95\% CI 0.15-0.83) among all women and HR 0.16 (95\% CI 0.04-0.68) among never-smoking women in the highest tertile of acrylamide intake versus the lowest], while there was no association with acrylamide intake among women with at least 1 copy of the gene.

There were four more interactions that remained statistically significant after adjustment for multiple testing, with the following SNPs: rs 1056827 in cytochrome P450, family 1, subfamily B, polypeptide 1 (CYP1B1) (Benjamini-Hochberg adjusted $p$ value 0.18$)$, rs2959008 and rs7173655 $\left(R^{2}\right.$ $0.79, D^{\prime} 0.92$ ) in cytochrome P450, family 11 , subfamily $A$, polypeptide 1 (CYP11A1) (Benjamini-Hochberg adjusted $p$ value 0.19 for both SNPs), and rs 1052133 in human 8-oxo-7,8-dihydroguanine DNA glycosylase 1 (hOGG1) (Benjamini-Hochberg adjusted $p$ value 0.19 ). Women homozygous for the wild-type allele of $C Y P 1 B 1$ were at a statistically significantly decreased acrylamide-associated risk of ER+ breast cancer, while women with at least 1 variant allele were not. Among never smokers, this pattern was not seen, although the interaction was nominally statistically significant ( $p$ interaction $=0.03$ ). In this subgroup, there was a statistically non-significant increase in risk in women with at least one variant allele, while there was no association between acrylamide and risk in women with two wild-type alleles. The two SNPs in CYP11A1 both showed that women homozygous for the wild-type allele were at a decreased acrylamide-associated risk while there was no association for women with at least one variant allele. This was seen both among all women and among never smokers. Only women with one or two variant alleles of rs 1052133 in $h O G G l$ were at a decreased acrylamide-associated risk of ER+ breast cancer. Women who were homozygous wild types did not show an association between acrylamide and $\mathrm{ER}+$ breast cancer. The effect modification was less clear among never smokers.

In Table 5, we show interactions with SNPs in (other) genes involved in acrylamide metabolism that are interesting because they have a higher a priori probability of modifying the association between acrylamide and cancer risk 
Table 4 Statistically significant interactions ${ }^{a}$ between SNPs and dietary acrylamide intake on the risk of estrogen receptor-positive breast cancer, 20.3 years of follow-up

\begin{tabular}{|c|c|c|c|c|c|c|c|c|c|}
\hline \multirow[t]{3}{*}{ SNP } & \multirow{3}{*}{$\begin{array}{l}\text { Acrylamide, } \\
\text { continuous } \\
\text { intake } \\
\text { HR } 10 \mu \mathrm{g} / \text { day }\end{array}$} & \multicolumn{6}{|c|}{ Acrylamide, tertiles of intake } & \multirow{2}{*}{\multicolumn{2}{|c|}{$\begin{array}{l}\text { Interaction } \\
p \text { for linear interaction }\end{array}$}} \\
\hline & & \multirow[t]{2}{*}{$N$ cases } & \multirow{2}{*}{$\begin{array}{l}\text { HR Ter- } \\
\text { tile } 1\end{array}$} & \multirow[t]{2}{*}{$N$ cases } & \multirow[t]{2}{*}{ HR Tertile 2} & \multirow[t]{2}{*}{$N$ cases } & \multirow[t]{2}{*}{ HR Tertile 3} & & \\
\hline & & & & & & & & Raw $p$ & $\begin{array}{l}\text { Benjamini- } \\
\text { Hochberg } \\
\text { adjusted } p \text { value }\end{array}$ \\
\hline \multicolumn{10}{|l|}{ All } \\
\hline $\begin{array}{l}C Y P 1 B 1, \\
\quad \text { rs } 1056827=0\end{array}$ & $0.87(0.78-0.98)$ & 150 & $\operatorname{Ref}(1.00)$ & 141 & $0.97(0.71-1.35)$ & 141 & $0.83(0.60-1.15)$ & 0.003 & 0.18 \\
\hline $\begin{array}{l}C Y P 1 B 1, \\
\quad \text { rs } 1056827=1\end{array}$ & $1.05(0.94-1.18)$ & 134 & $\operatorname{Ref}(1.00)$ & 143 & $1.08(0.77-1.50)$ & 132 & $1.06(0.75-1.49)$ & & \\
\hline \multicolumn{10}{|l|}{ Never smokers } \\
\hline $\begin{array}{l}C Y P 1 B 1, \\
\quad \text { rs } 1056827=0\end{array}$ & $0.95(0.81-1.10)$ & 84 & $\operatorname{Ref}(1.00)$ & 78 & $1.06(0.68-1.66)$ & 86 & $0.98(0.64-1.51)$ & 0.03 & 0.44 \\
\hline $\begin{array}{l}C Y P 1 B 1, \\
\quad \text { rs } 1056827=1\end{array}$ & $1.16(0.99-1.36)$ & 68 & $\operatorname{Ref}(1.00)$ & 90 & $1.49(0.97-2.30)$ & 78 & $1.35(0.87-2.10)$ & & \\
\hline \multicolumn{10}{|l|}{ All } \\
\hline $\begin{array}{l}C Y P 11 A 1, \\
\quad \text { rs2959008 }=0\end{array}$ & $0.83(0.73-0.95)$ & 133 & $\operatorname{Ref}(1.00)$ & 135 & $1.03(0.71-1.50)$ & 109 & $0.73(0.51-1.06)$ & 0.01 & 0.19 \\
\hline $\begin{array}{l}C Y P 11 A 1, \\
\quad \text { rs } 2959008=1\end{array}$ & $1.04(0.94-1.16)$ & 153 & $\operatorname{Ref}(1.00)$ & 151 & $1.05(0.77-1.42)$ & 164 & $1.10(0.81-1.50)$ & & \\
\hline \multicolumn{10}{|l|}{ Never smokers } \\
\hline $\begin{array}{l}C Y P 11 A 1, \\
\quad \text { rs2959008 }=0\end{array}$ & $0.87(0.74-1.02)$ & 73 & $\operatorname{Ref}(1.00)$ & 77 & $1.42(0.86-2.35)$ & 66 & $0.92(0.56-1.49)$ & 0.02 & 0.41 \\
\hline $\begin{array}{l}C Y P 11 A 1, \\
\quad \text { rs } 2959008=1\end{array}$ & $1.18(1.02-1.36)$ & 80 & $\operatorname{Ref}(1.00)$ & 92 & $1.23(0.82-1.86)$ & 98 & $1.35(0.90-2.03)$ & & \\
\hline \multicolumn{10}{|l|}{ All } \\
\hline $\begin{array}{l}C Y P 11 A 1, \\
\quad \text { rs } 7173655=0\end{array}$ & $0.84(0.74-0.95)$ & 139 & $\operatorname{Ref}(1.00)$ & 142 & $1.07(0.76-1.51)$ & 108 & $0.71(0.50-1.02)$ & 0.01 & 0.19 \\
\hline $\begin{array}{l}C Y P 11 A 1, \\
\quad \text { rs7173655 =1 }\end{array}$ & $1.03(0.93-1.14)$ & 146 & $\operatorname{Ref}(1.00)$ & 144 & $1.02(0.75-1.40)$ & 165 & $1.11(0.81-1.452)$ & & \\
\hline \multicolumn{10}{|l|}{ Never smokers } \\
\hline $\begin{array}{l}C Y P 11 A 1, \\
\quad \text { rs } 7173655=0\end{array}$ & $0.89(0.75-1.04)$ & 74 & $\operatorname{Ref}(1.00)$ & 80 & $1.33(0.83-2.14)$ & 65 & $0.89(0.55-1.43)$ & 0.02 & 0.41 \\
\hline $\begin{array}{l}C Y P 11 A 1, \\
\quad \text { rs } 7173655=1\end{array}$ & $1.17(1.02-1.34)$ & 78 & $\operatorname{Ref}(1.00)$ & 89 & $1.27(0.83-1.93)$ & 99 & $1.43(0.94-2.17)$ & & \\
\hline \multicolumn{10}{|l|}{ All } \\
\hline $\begin{array}{l}\text { GSTT1 present, } \\
\text { rs140309 }\end{array}$ & $0.97(0.90-1.06)$ & 252 & $\operatorname{Ref}(1.00)$ & 251 & $1.02(0.80-1.30)$ & 255 & $1.00(0.78-1.27)$ & 0.01 & 0.19 \\
\hline $\begin{array}{l}\text { GSTT1 deleted, } \\
\text { rs140309 }\end{array}$ & $0.66(0.48-0.91)$ & 34 & $\operatorname{Ref}(1.00)$ & 35 & $1.33(0.55-3.21)$ & 18 & $0.35(0.15-0.83)$ & & \\
\hline \multicolumn{10}{|l|}{ Never smokers } \\
\hline $\begin{array}{l}\text { GSTT1 present, } \\
\text { rs140309 }\end{array}$ & $1.08(0.97-1.21)$ & 132 & $\operatorname{Ref}(1.00)$ & 148 & $1.26(0.91-1.76)$ & 152 & $1.29(0.93-1.78)$ & 0.01 & 0.41 \\
\hline $\begin{array}{l}\text { GSTT1 deleted, } \\
\text { rs140309 }\end{array}$ & $0.61(0.37-0.99)$ & 21 & $\operatorname{Ref}(1.00)$ & 21 & $0.74(0.21-2.68)$ & 12 & $0.16(0.04-0.68)$ & & \\
\hline \multicolumn{10}{|l|}{ All } \\
\hline $\begin{array}{l}\text { hOGG1, } \\
\quad \text { rs } 1052133=0\end{array}$ & $1.03(0.94-1.14)$ & 152 & $\operatorname{Ref}(1.00)$ & 161 & $1.08(0.79-1.46)$ & 182 & $1.19(0.89-1.60)$ & 0.02 & 0.19 \\
\hline $\begin{array}{l}h O G G 1, \\
\quad \text { rs } 1052133=1\end{array}$ & $0.81(0.70-0.93)$ & 134 & $\operatorname{Ref}(1.00)$ & 125 & $0.91(0.63-1.31)$ & 91 & $0.56(0.37-0.83)$ & & \\
\hline
\end{tabular}


Table 4 (continued)

\begin{tabular}{|c|c|c|c|c|c|c|c|c|c|}
\hline \multirow[t]{3}{*}{ SNP } & \multirow{3}{*}{$\begin{array}{l}\text { Acrylamide, } \\
\text { continuous } \\
\text { intake } \\
\text { HR } 10 \mu \mathrm{g} / \text { day }\end{array}$} & \multicolumn{6}{|c|}{ Acrylamide, tertiles of intake } & \multirow{2}{*}{\multicolumn{2}{|c|}{$\begin{array}{l}\text { Interaction } \\
p \text { for linear interaction }\end{array}$}} \\
\hline & & \multirow[t]{2}{*}{$N$ cases } & \multirow{2}{*}{$\begin{array}{l}\text { HR Ter- } \\
\text { tile } 1\end{array}$} & \multirow[t]{2}{*}{$N$ cases } & \multirow[t]{2}{*}{ HR Tertile 2} & \multirow[t]{2}{*}{$N$ cases } & \multirow[t]{2}{*}{ HR Tertile 3} & & \\
\hline & & & & & & & & Raw $p$ & $\begin{array}{l}\text { Benjamini- } \\
\text { Hochberg } \\
\text { adjusted } p \text { value }\end{array}$ \\
\hline \multicolumn{10}{|l|}{ Never smokers } \\
\hline $\begin{array}{l}\text { hOGG1, } \\
\quad \text { rs } 1052133=0\end{array}$ & $1.07(0.95-1.21)$ & 78 & $\operatorname{Ref}(1.00)$ & 92 & $1.39(0.93-2.07)$ & 112 & $1.36(0.93-2.00)$ & 0.26 & 0.90 \\
\hline $\begin{array}{l}\text { hOGG1, } \\
\quad \operatorname{rs} 1052133=1\end{array}$ & $0.95(0.78-1.15)$ & 75 & $\operatorname{Ref}(1.00)$ & 77 & $1.06(0.63-1.76)$ & 52 & $0.81(0.48-1.38)$ & & \\
\hline
\end{tabular}

Hazard ratios (HR) are adjusted for age (years), age at menarche (years), age at menopause (years), age at first childbirth (nulliparous, 15-19 years, 20-24 years, 25-29 years, $\geq 30$ years), parity ( $n$ children), ever use of oral contraceptives (yes/no), ever use of postmenopausal hormone treatment (yes/no), height $(\mathrm{cm})$, body mass index $\left(\mathrm{kg} / \mathrm{m}^{2}\right)$, educational level (4 levels) energy intake (kcal/day), history of benign breast disease, family history of breast cancer, and in the analyses for all women: smoking status (never/ex/current smoker), smoking quantity ( $n$ cigarettes/day), smoking duration (smoking years)

${ }^{\S}$ Proportion of false positives threshold set at 0.2

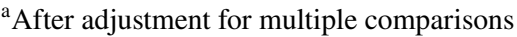

than the other selected SNPs. Rs915906, rs2480258, and rs6413432 in CYP2E1 did not show an interaction with acrylamide intake among all women, nor among neversmoking women. There was also no interaction between the deletion of GSTM1 and acrylamide, or SNPs in other acrylamide-metabolizing genes.

Supplemental Table 3 shows the nominally statistically significant interactions that did not withstand adjustment for multiple testing, namely: rs1800566 in NQO1 and rs6838248 in SLC7A11 specifically among never smokers.

Finally, there were some clear differences in the association with acrylamide between genotypes without a statistically significant interaction, namely for: rs2070959 in UGTIA, rs11252859 in AKRIC1, rs11252887 in AKRIC2, rs 1280350 in $M G C 12965$, rs 1042157 and rs6839 in SULT1A1, rs737865 in COMT, rs10432782 in SOD1, rs4880 and rs5746136 in SOD2, rs1047303 in the HSD3B1/B2 gene cluster, rs6259 in $S H B G$, rs6759180 in $R R M 2$, and rs2228001 in XPC (Supplemental Table 3).

\section{Discussion}

As far as we know, this is the first study to analyze acrylamide-gene interactions for breast cancer risk. We observed interactions between acrylamide intake and rs1056827 in CYP1B1, rs2959008 and rs7173655 in CYP11A1, the GSTT1 gene deletion, and rs 1052133 in $h O G G 1$. These interactions remained statistically significant after adjustment for multiple testing.

Contrary to what we found in a previous analysis for ER+ breast cancer albeit not statistically significant [3], acrylamide intake was not positively associated with $\mathrm{ER}+$ breast cancer risk among never smokers in the current analysis. In addition, when we restricted our analyses to 13.3 years of follow-up (as in the previous analysis), acrylamide intake was not positively associated with ER+breast cancer risk. The explanation for this discrepancy is probably that different case sets were used in the analyses. In the previous analyses, cases were derived from the Dutch Pathology Registry and four regional Dutch cancer registries because only those 4 routinely recorded information on estrogen receptor status at that time. Cases for the current analysis originated from all nine regional Dutch cancer registries, the Dutch Pathology Registry and the causes of death registry, and so there were more cases in the present analysis. In the previous analysis, the percentage of cases with missing info on estrogen receptor status was quite high (57\%) and we checked whether cases with known estrogen receptor status differed from cases with unknown receptor status with regard to tumor and other characteristics, such as BMI and age. This was not the case but it is still possible that selection of a specific subgroup of ER+ cases occurred and that the positive association between acrylamide intake and $\mathrm{ER}+$ breast cancer risk was restricted to this group. Among all women in the current analysis, there was a tendency towards an inverse association.

Glycidamide (the epoxide metabolite of acrylamide formed through metabolism by CYP2E1) is often thought to be responsible for acrylamide-induced carcinogenesis due to genotoxicity (mutagenicity and/or clastogenicity [24]). Studying the modifying effect of SNPs in CYP2E1 on the association between acrylamide and cancer risk may thus contribute important information on the causality of the 


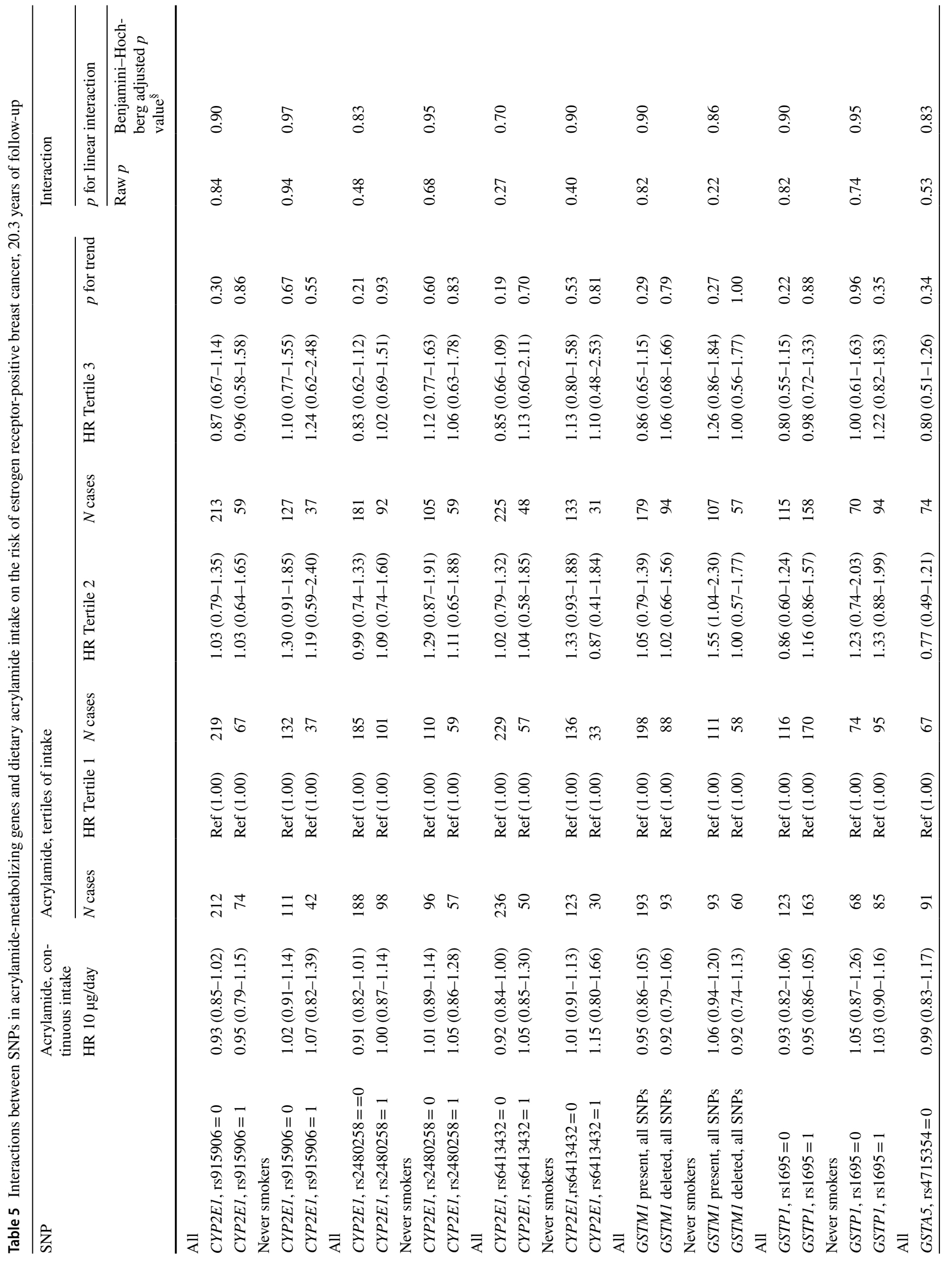




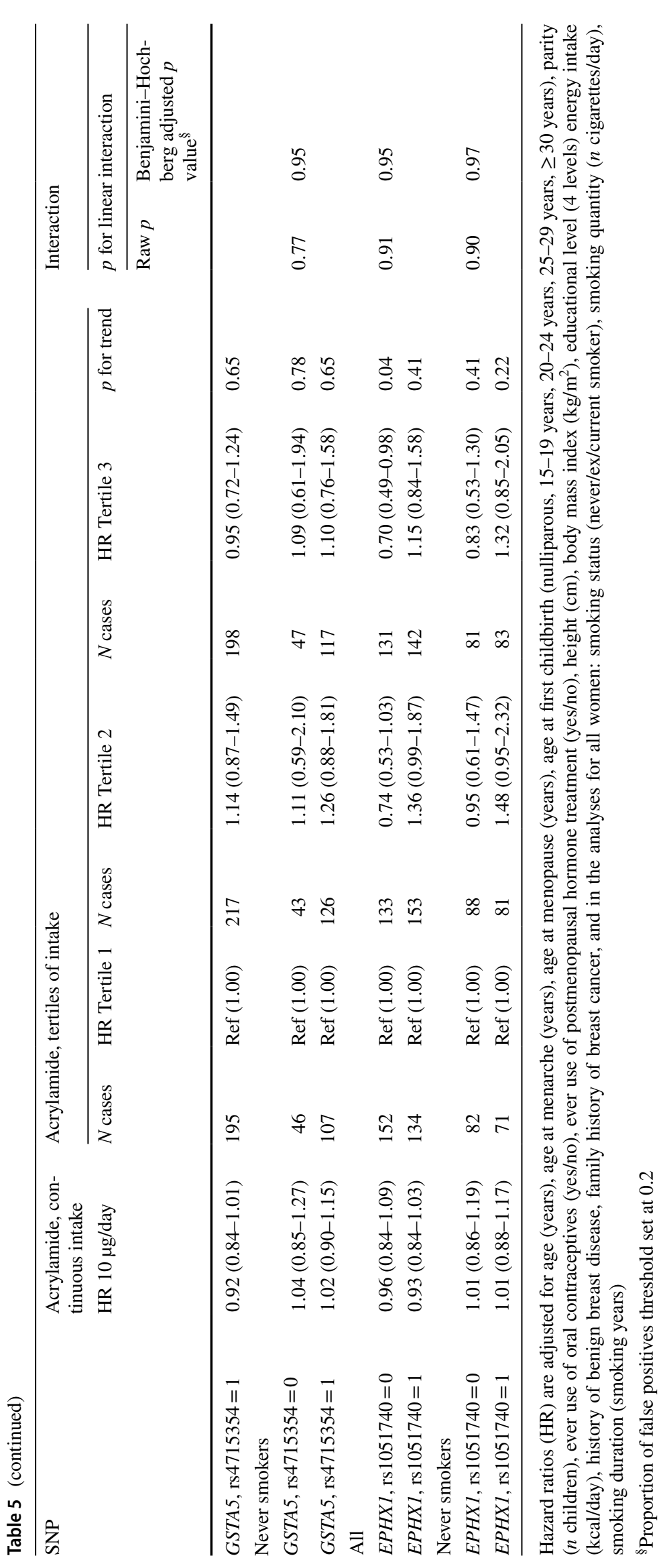


association. We observed no interaction between 3 SNPS in CYP2E1 and acrylamide intake for ER+ breast cancer risk and there were no clear differences in the risk between the genotypes, contrary to what was observed for endometrial [7] and ovarian cancer [8]. We have no clear explanation for this inconsistency but an explanation could be that there is no association between acrylamide intake and breast cancer risk or that for breast cancer, acrylamide and glycidamide are (roughly) equally responsible for the carcinogenic effect. The three studied CYP2E1 SNPs are in the intronic region of the gene and there is no clear information about their functionality but the wild-type allele of rs6413432 has been shown to be associated with an increased risk of prostate cancer [25] and other cancers such as lung cancer [26].

We observed that women with a homozygous deletion of GSTT1 (deletion represented by rs140309) were at a decreased acrylamide-associated risk of ER+breast cancer but the number of cases with a homozygous GSTT1 deletion was rather small $(n=87)$. In contrast, we previously observed women with at least one copy of the GSTT1 gene to be at an increased acrylamide-associated risk of endometrial and ovarian cancer $[7,8]$. There was no clear difference in the association between acrylamide intake and ER+breast cancer risk between the genotypes of GSTM1.

We observed a statistically significant interaction between acrylamide intake and rs1056827 in CYP1B1. Women who were homozygous wild types for this allele were at a decreased risk of acrylamide-associated ER+ breast cancer. In never smokers, the interaction was less clear. CYP1B1 is a phase I biotransformation enzyme involved in the metabolism of various exogenous and endogenous compounds and is mainly expressed in endocrine tissues like the endometrium, ovarium and breast. CYP1B1 converts estrogens to hydroxy metabolites (catechol estrogens) which are potent estrogens and furthermore CYP1B1 oxidizes catechol estrogens to chemically reactive semiquinone and quinone intermediates that can bind to DNA and cause mutations. Exposure of mouse spermatocytes to acrylamide and glycidamide led to increased $C Y P 1 B 1$ expression [27], while glycidamide exposure led to decreased $C Y P 1 B 1$ expression in human epithelial cells [28]. Possible explanations for this discrepancy are species, cell or dose differences. The variant allele of rs 1056827 has been shown to have increased enzyme activity and to be associated with an increased breast cancer risk [29]. Due to the scarcity of literature and the inconsistency in the relationship between acrylamide and CYP1B1 activity, it is currently impossible to say whether the observed interaction is biologically plausible.

Acrylamide interacted statistically significantly with 2 SNPs in CYP11A1: rs2959008 and rs7173655; acrylamide intake was associated with a decreased ER+ breast cancer risk in women who were homozygous for the wild type of these alleles. CYP11A1 is involved in the formation of pregnenolone from cholesterol, the first and rate-limiting step in steroid hormone synthesis. Both CYP11A1 SNPs are in the intronic region of the gene and there is no information available about their functionality. The variant allele of rs2959008 was associated with a decreased breast cancer risk in Han Chinese [30]. There is no literature on rs7173655 and breast cancer risk but the variant allele was associated with an increased endometrial cancer risk [31]. Acrylamide exposure of male Fischer 344 rats led to increased expression of CYP11A1 in reproductive tissues [32] but to decreased CYP11A1 expression in testis tissue of male Sprague-Dawley rats [33]. This discrepancy may be due to differences in rat strains or doses of acrylamide, or both. Thus, again due to the scarcity and inconsistency of data, it is not currently possible to judge the biological plausibility of the interaction between acrylamide and these CYP11A1 SNPs.

Progesterone opposes the proliferative effect of estrogens in the endometrium and ovaries while it is thought to have proliferative effects in mammary tissue [34]. A mechanism by which acrylamide may increase risks of endometrial and ovarian cancer and decrease the risk of ER+ breast cancer is through an effect on progesterone. However, this is highly speculative, also due to the fact that we did not see interaction between acrylamide and the CYP2E1 SNPs which leaves the possibility that there may not be a true association between acrylamide intake and breast cancer risk. If true, the interactions between acrylamide and HSD3B SNPs for ovarian cancer [8] and between acrylamide and the $C Y P 1 B 1$ and CYP11A1 SNPs for breast cancer in the current study give some indications that acrylamide may interfere with progesterone metabolism. However, there was no association between acrylamide intake and progesterone in a crosssectional study in premenopausal women [35]. In animals, acrylamide has repeatedly been shown to decrease progesterone levels [36-38]. Nevertheless, we strongly encourage more research on the possible effect of acrylamide on progesterone metabolism in humans.

Only women with variant alleles of rs1052133 in hOGG1 showed an inverse association between acrylamide intake and ER+ breast cancer risk. The hOGG1 gene is part of the base excision DNA repair pathway, responsible for the excision of 8-oxoguanine (8-oxoG), a mutagenic DNA base byproduct of reactive oxygen species. Although the variant allele is hypothesized to have decreased enzyme activity $[39,40]$, a recent meta-analysis showed that it is associated with a decreased risk of breast cancer among Europeans [41], while another meta-analysis did not show an association [42]. Because of these apparent contradictions, it is currently impossible to speculate about the possible mechanism by which this SNP could modify the association between acrylamide intake and ER+ breast cancer risk.

There were two other nominally statistically significant interactions between acrylamide intake and other SNPs: 
rs1800566 in NQO1 and rs6838248 in SLC7A11. Additionally, there were some clear differences in the association with acrylamide between genotypes without a statistically significant interaction, for: rs2070959 in UGT1A, rs1 1252859 in $A K R 1 C 1, \mathrm{rs} 11252887$ in $A K R 1 C 2, \mathrm{rs} 1280350$ in $M G C 12965$, rs1042157 and rs6839 in SULT1A1, rs737865 in COMT, rs10432782 in SOD1, rs4880 and rs5746136 in $S O D 2$, rs 1047303 in the $H S D 3 B 1 / B 2$ gene cluster, rs6259 in $S H B G$, rs6759180 in RRM2, and rs2228001 in XPC. For all these SNPs it is even more important that the interaction between acrylamide intake and these SNPs is corroborated in other studies to be able to judge whether our findings represent true interactions or not.

This study has some limitations. Acrylamide levels vary considerably within foods due to processing and varieties used. Despite the large variation in acrylamide levels within foods, acrylamide intake as assessed by food frequency questionnaires and acrylamide to hemoglobin adducts (biomarker for exposure) have been shown to correlate moderately in several studies, e.g. [43, 44]. Thus, the food frequency questionnaire is able to estimate the rank order of acrylamide intake among study populations. In addition, we correlated the assessed acrylamide intake (based on mean acrylamide levels per food) and the measured acrylamide content of 24-hour Dutch duplicate diets, for which the participants had written down exactly what and how much they ate and drank. The correlation was very high $(r=0.82$, $p<0.001$ ) [45]. To conclude, assessing acrylamide intake through food frequency questionnaires is not perfect and entails some random measurement error, which pushes the point estimate towards the null, but it is useful for studying the link between acrylamide intake and cancer risk. Data on diet and covariables obtained from the questionnaire were collected only once, at baseline. Some of the characteristics (e.g., diet, BMI) will certainly have changed over time after baseline. One of the reasons to select an elderly population for the study was that older people tend to have more stable dietary habits. The changes that have occurred despite this will have resulted in random measurement error, pushing the point estimate of the hazard ratio towards the null.

Some of the nominally statistically significant interactions that we observed are, without a doubt, chance findings. However, it is of interest that some of the genes that we observed to interact with acrylamide for ER+ breast cancer risk or that showed clear differences in risk between the genotypes also did so for endometrial [7] and ovarian cancer [8]: GSTT1, $A K R 1 C 1, N Q O 1$, the $H S D 3 B 1 / B 2$ gene cluster, $X P C$, and $M G C 12965$. These genes therefore deserve attention in future studies.

The strengths of this study are the complete follow-up and its prospective nature.

In conclusion, we did not observe a positive association between dietary acrylamide intake and ER+ breast cancer risk. Unexpectedly, our results gave some indications for an inverse association. Unlike for endometrial and ovarian cancer, there was no interaction between acrylamide intake and CYP2E1 SNPs for ER+ breast cancer risk. After adjustment for multiple testing, this study showed statistically significant interactions between rs 1056827 in CYP1B1, rs2959008 and rs7173655 in CYP11A1, the deletion of GSTT1, and rs 1052133 in $h O G G l$ and acrylamide intake for ER+breast cancer risk. Based on this study and analyses for endometrial and ovarian cancer, we recommend follow-up of interactions between acrylamide intake and genetic polymorphisms in $C Y P 1 B 1, C Y P 11 A 1$, the $H S D 3 B 1 / B 2$ gene cluster, CYP2E1, GSTs, hOGG1, AKRIC1, NQO1, GPX1, XPC and $M G C 12965$, and additional research on the possible effect of acrylamide on progesterone metabolism in humans.

Acknowledgements This study was funded by the Dutch Cancer Society (KWF), Grant number: UM 2011-5123. Janneke Hogervorst is a postdoctoral research fellow from the Research Foundation-Flanders (FWO), no. 12J9516N. The authors thank the study participants, the Netherlands Cancer Registry, the Dutch Pathology Registry, and the Biobank of the Maastricht University Medical Center. We thank Dr. Sandra Bausch as initiator of the NLCS study, together with Prof. Piet van den Brandt. We also thank Sacha van de Crommert, Jolanda Nelissen, Conny de Zwart, Ellen Dutman, Henny Brants, and Annemie Pisters for their assistance with data entry or data management, Harry van Montfort for programming assistance, and Simone van Breda, Stijn Lumeij, Kristien Lemmens, Joy Goessens, and Leonie Jonkers for technical assistance with DNA isolation and genotyping.

\section{Compliance with ethical standards}

Conflict of interest The authors have no conflict of interest to declare. Leo Schouten was compensated for being on an expert panel of the European Food Safety Authority that contributed to the 2015 risk assessment on acrylamide.

Open Access This article is distributed under the terms of the Creative Commons Attribution 4.0 International License (http://creativeco mmons.org/licenses/by/4.0/), which permits unrestricted use, distribution, and reproduction in any medium, provided you give appropriate credit to the original author(s) and the source, provide a link to the Creative Commons license, and indicate if changes were made.

\section{References}

1. Maier A, Kohrman-Vincent M, Hertzberg R, Allen B, Haber LT, Dourson M (2012) Critical review of dose-response options for F344 rat mammary tumors for acrylamide - additional insights based on mode of action. Food Chem Toxicol 50(5):1763-1775

2. Pelucchi C, Bosetti C, Galeone C, La Vecchia C (2015) Dietary acrylamide and cancer risk: an updated meta-analysis. Int J Cancer 136(12):2912-2922

3. Pedersen GS, Hogervorst JG, Schouten LJ, Konings EJ, Goldbohm RA, van den Brandt PA (2010) Dietary acrylamide intake and estrogen and progesterone receptor-defined postmenopausal breast cancer risk. Breast Cancer Res Treat 122(1):199-210 
4. Olesen PT, Olsen A, Frandsen H, Frederiksen K, Overvad K, Tjonneland A (2008) Acrylamide exposure and incidence of breast cancer among postmenopausal women in the Danish Diet, Cancer and Health Study. Int J Cancer 122(9):2094-2100

5. Althuis MD, Fergenbaum JH, Garcia-Closas M, Brinton LA, Madigan MP, Sherman ME (2004) Etiology of hormone receptordefined breast cancer: a systematic review of the literature. Cancer Epidemiol Biomarkers Prev 13(10):1558-1568

6. Besaratinia A, Pfeifer GP (2007) A review of mechanisms of acrylamide carcinogenicity. Carcinogenesis 28(3):519-528

7. Hogervorst JG, van den Brandt PA, Godschalk RW, van Schooten FJ, Schouten LJ (2016) The influence of single nucleotide polymorphisms on the association between dietary acrylamide intake and endometrial cancer risk. Sci Rep 6:34902

8. Hogervorst JG, van den Brandt PA, Godschalk RW, van Schooten FJ, Schouten LJ (2017) Interactions between dietary acrylamide intake and genes for ovarian cancer risk. Eur J Epidemiol 32(5):431-441

9. van den Brandt PA, Goldbohm RA, van 't Veer P, Volovics A, Hermus RJ, Sturmans F (1990) A large-scale prospective cohort study on diet and cancer in The Netherlands. J Clin Epidemiol 43(3):285-295

10. van den Brandt PA, Schouten LJ, Goldbohm RA, Dorant E, Hunen PM (1990) Development of a record linkage protocol for use in the Dutch Cancer Registry for Epidemiological Research. Int J Epidemiol 19(3):553-558

11. Goldbohm RA, van den Brandt PA, Brants HA, van't Veer P, Al M, Sturmans F, Hermus RJ (1994) Validation of a dietary questionnaire used in a large-scale prospective cohort study on diet and cancer. Eur J Clin Nutr 48(4):253-265

12. Goldbohm RA, van 't Veer P, van den Brandt PA, van 't Hof MA, Brants HA, Sturmans F, Hermus RJ (1995) Reproducibility of a food frequency questionnaire and stability of dietary habits determined from five annually repeated measurements. Eur J Clin Nutr 49(6):420-429

13. Hogervorst JG, Schouten LJ, Konings EJ, Goldbohm RA, van den Brandt PA (2007) A prospective study of dietary acrylamide intake and the risk of endometrial, ovarian, and breast cancer. Cancer Epidemiol Biomarkers Prev 16(11):2304-2313

14. Cline RE, Laurent NM, Foran DR (2003) The fingernails of Mary Sullivan: developing reliable methods for selectively isolating endogenous and exogenous DNA from evidence. J Forensic Sci 48(2):328-333

15. Hogervorst JG, Godschalk RW, van den Brandt PA, Weijenberg MP, Verhage BA, Jonkers L, Goessens J, Simons CC, Vermeesch JR, van Schooten FJ et al (2014) DNA from nails for genetic analyses in large-scale epidemiologic studies. Cancer Epidemiol Biomarkers Prev 23(12):2703-2712

16. Gabriel S, Ziaugra L, Tabbaa D (2009) SNP genotyping using the Sequenom MassARRAY iPLEX platform. Curr Protoc Hum Genet Chap 2:Unit 212

17. Geybels MS, van den Brandt PA, Schouten LJ, van Schooten FJ, van Breda SG, Rayman MP, Green FR, Verhage BA (2014) Selenoprotein gene variants, toenail selenium levels, and risk for advanced prostate cancer. J Nat Cancer Inst 106(3):dju003

18. Deckers IA, van den Brandt PA, van Engeland M, van Schooten FJ, Godschalk RW, Keszei AP, Schouten LJ (2015) Polymorphisms in genes of the renin-angiotensin-aldosterone system and renal cell cancer risk: Interplay with hypertension and intakes of sodium, potassium and fluid. Int J Cancer 136(5):1104-1116

19. Schettgen T, Rossbach B, Kutting B, Letzel S, Drexler H, Angerer J (2004) Determination of haemoglobin adducts of acrylamide and glycidamide in smoking and non-smoking persons of the general population. Int J Hyg Environ Health 207(6):531-539
20. Bergmark E (1997) Hemoglobin adducts of acrylamide and acrylonitrile in laboratory workers, smokers and nonsmokers. Chem Res Toxicol 10(1):78-84

21. Benjamini Y, Hochberg Y (1995) Controlling the false discovery rate: a practical and powerful approach to multiple testing. J R Statist Soc 57:289-300

22. Geybels MS, van den Brandt PA, van Schooten FJ, Verhage BA (2015) Oxidative stress-related genetic variants, pro- and antioxidant intake and status, and advanced prostate cancer risk. Cancer Epidemiol Biomarkers Prev 24(1):178-186

23. Kim C, Zheng T, Lan Q, Chen Y, Foss F, Chen X, Holford T, Leaderer B, Boyle P, Chanock SJ et al (2012) Genetic polymorphisms in oxidative stress pathway genes and modification of BMI and risk of non-Hodgkin lymphoma. Cancer Epidemiol Biomarkers Prev 21(5):866-868

24. Wang RS, McDaniel LP, Manjanatha MG, Shelton SD, Doerge DR, Mei N (2010) Mutagenicity of acrylamide and glycidamide in the testes of big blue mice. Toxicol Sci 117(1):72-80

25. Ferreira PM, Medeiros R, Vasconcelos A, Costa S, Pinto D, Morais A, Oliveira J, Lopes C (2003) Association between CYP2E1 polymorphisms and susceptibility to prostate cancer. Eur J Cancer Prev 12(3):205-211

26. Su XL, Bin B, Cui HW, Ran MR (2011) Cytochrome P450 2E1 $\mathrm{RsaI} / \mathrm{PstI}$ and DraI polymorphisms are risk factors for lung cancer in mongolian and han population in inner Mongolia. Chin J Cancer Res 23(2):107-111

27. Nixon BJ, Katen AL, Stanger SJ, Schjenken JE, Nixon B, Roman SD (2014) Mouse spermatocytes express CYP2E1 and respond to acrylamide exposure. PloS one 9(5):e94904

28. Clement FC, Dip R, Naegeli H (2007) Expression profile of human cells in culture exposed to glycidamide, a reactive metabolite of the heat-induced food carcinogen acrylamide. Toxicology 240(1-2):111-124

29. Reding KW, Weiss NS, Chen C, Li CI, Carlson CS, Wilkerson HW, Farin FM, Thummel KE, Daling JR, Malone KE (2009) Genetic polymorphisms in the catechol estrogen metabolism pathway and breast cancer risk. Cancer Epidemiol Biomarkers Prev 18(5): 1461-1467

30. Sun M, Yang X, Ye C, Xu W, Yao G, Chen J, Li M (2012) Riskassociation of CYP11A1 polymorphisms and breast cancer among Han Chinese women in Southern China. Int J Mol Sci 13(4):4896-4905

31. Terry K, McGrath M, Lee IM, Buring J, De Vivo I (2010) Genetic variation in CYP11A1 and StAR in relation to endometrial cancer risk. Gynecol Oncol 117(2):255-259

32. Camacho L, Latendresse JR, Muskhelishvili L, Patton R, Bowyer JF, Thomas M, Doerge DR (2012) Effects of acrylamide exposure on serum hormones, gene expression, cell proliferation, and histopathology in male reproductive tissues of Fischer 344 rats. Toxicol Lett 211(2):135-143

33. Yang HJ, Lee SH, Jin Y, Choi JH, Han DU, Chae C, Lee MH, Han $\mathrm{CH}$ (2005) Toxicological effects of acrylamide on rat testicular gene expression profile. Reprod Toxicol 19(4):527-534

34. Diep CH, Daniel AR, Mauro LJ, Knutson TP, Lange CA (2015) Progesterone action in breast, uterine, and ovarian cancers. J Mol Endocrinol 54(2):R31-53

35. Hogervorst JG, Fortner RT, Mucci LA, Tworoger SS, Eliassen AH, Hankinson SE, Wilson KM (2013) Associations between dietary acrylamide intake and plasma sex hormone levels. Cancer Epidemiol Biomarkers Prev 22(11):2024-2036

36. Lebda M, Gad S, Gaafar H (2014) Effects of lipoic acid on acrylamide induced testicular damage. Mater Sociomed 26(3):208-212

37. Shuming C, Jilin F, Xichun Z (2009) The moderating role of dark soy sauce to acrylamide-induced oxidative stress and neurophysiological perturbations in rats. Toxicol Mech Methods 19(6-7):434-440 
38. Wei Q, Li J, Li X, Zhang L, Shi F (2014) Reproductive toxicity in acrylamide-treated female mice. Reprod Toxicol 46:121-128

39. Kohno T, Shinmura K, Tosaka M, Tani M, Kim SR, Sugimura H, Nohmi T, Kasai H, Yokota J (1998) Genetic polymorphisms and alternative splicing of the hOGG1 gene, that is involved in the repair of 8-hydroxyguanine in damaged DNA. Oncogene 16(25):3219-3225

40. Lee AJ, Hodges NJ, Chipman JK (2005) Interindividual variability in response to sodium dichromate-induced oxidative DNA damage: role of the Ser326Cys polymorphism in the DNA-repair protein of 8-oxo-7,8-dihydro-2'-deoxyguanosine DNA glycosylase 1. Cancer Epidemiol Biomarkers Prev 14(2):497-505

41. Yuan Y, Chen F, Zhao GH, Liu J, Zhang HX, Hu XS (2007) A comparative study of acrylamide formation induced by microwave and conventional heating methods. J Food Sci 72(4):C212-216

42. Gu D, Wang M, Zhang Z, Chen J (2010) Lack of association between the hOGG1 Ser326Cys polymorphism and breast cancer risk: evidence from 11 case-control studies. Breast Cancer Res Treat 122(2):527-531

43. Wilson KM, Bälter K, Adami HO, Grönberg H, Vikström AC, Paulsson B, Törnqvist M, Mucci LA (2009) Acrylamide exposure measured by food frequency questionnaire and hemoglobin adduct levels and prostate cancer risk in the Cancer of the Prostate in Sweden Study. Int J Cancer 124(10):2384-2390

44. Wilson KM, Vesper HW, Tocco P, Sampson L, Rosén J, Hellenäs KE, Törnqvist M, Willett WC (2009) Validation of a food frequency questionnaire measurement of dietary acrylamide intake using hemoglobin adducts of acrylamide and glycidamide. Cancer Causes Control 20(3):269-278

45. Konings EJ, Hogervorst JG, van Rooij L, Schouten LJ, Sizoo EA, van Egmond HP, Goldbohm RA, van den Brandt PA (2010) Validation of a database on acrylamide for use in epidemiological studies. Eur J Clin Nutr 64(5):534-540 